\title{
Computational Math, Science, and Technology (CMST): A Strategy to Improve STEM Workforce and Pedagogy to Improve Math and Science Education ${ }^{\star}$
}

\author{
O. Yaşar, L. Little, R. Tuzun, K. Rajasethupathy, J. Maliekal, and M. Tahar \\ CMST Institute, State University of New York, College at Brockport, NY 14420 \\ \{oyasar, llittle, rtuzun, kraja, jmalieka, mtahar\}@brockport.edu
}

\begin{abstract}
Integrated approach to education in science, technology, engineering, and mathematics (STEM) has recently become a common practice. Technologies such as wireless graphing calculators, electronic whiteboards, and computers help engage students in classroom activities. Modeling and simulation software allow experimentation without usual prerequisites while enabling a pedagogical approach to display interconnectedness of math and science. Controlled simulations and layered approach to learning seem to offer long-sought support for inquiry-based curricula in public schools. Today's jobs require multiple skills, necessitating a broader college education. While students with multiple majors can be seen on college campuses, the overall number of degree holders in technical fields has gone down steadily. A handful of institutions have established multidisciplinary programs to adjust to these concerns and to better serve diverse interests of students.
\end{abstract}

\section{Introduction}

Estimates of the size of the STEM workforce in the USA varies between 3-10 million individuals, depending on the definition and perspective used. For the period from 2000 to 2010, Bureau of Labor Statistics predict that employment in science and engineering occupations will increase about 3 times faster than the growth rate for all occupations 1. The economy as a whole is expected to provide approximately $15 \%$ more jobs over this decade, with employment opportunities for STEM jobs expected to increase by 2.2 million jobs, or about 47 percent. Approximately, 86 percent of the projected increase in STEM jobs is in computer-related occupations.

This projected trend is supported by the current and past data released by the American Institute of Physics [2] and the U.S. National Science Foundation. According to AIP survey, physics graduates indicated that the three most important skills in their jobs were scientific problem solving, synthesizing information, and mathematical skills. The importance of math and computer skills

\footnotetext{
* Authors acknowledge support by National Science Foundation's Math and Science Partnership grant (EHR-0226962) and Cyberinfrastructure grant (SCI-0520036).
} 
is also evidenced in National Science Board's 1996 report [3]: $74 \%$ of math and computer science doctorates worked in the same field as their degree versus 57 $\%$ in physical sciences. A similar trend is seen at the bachelor's level (35\% versus $22 \%$ ). While there is a great demand for math and computer skills, this data also shows the importance of a science education that may open doors to a variety of jobs. An education combining math and computer skills with a science or an engineering field would be a valuable investment. This is particularly important for undergraduate students because the likelihood of being employed outside of one's field is high for most disciplines. Over the past several years, some science and engineering disciplines have added more math and computing courses in their curricula while math and computer science disciplines increased student exposure to areas of applications (see the ABET accreditation requirements for Computing programs). A more dramatic approach, yet still in infancy, has been creation of a new interdisciplinary field, namely computational science and engineering, which offers an integrated approach to STEM education.

While there seems to be a great demand for STEM workers, there is a fundamental problem with STEM education within the USA. The percentage of bachelor's degrees in STEM has steadily gone down; from 35\% in 1966 to $31 \%$ in 2001 4. The same trend is seen with master's (29\% to $21 \%$ ) and doctoral (64\% to $62 \%$ ) degrees. When one looks at the pre-college student achievement in math and science, the lack of interest in STEM becomes obvious. The United States ranks at the bottom of the 12th grade TIMSS (Trends in International Mathematics and Science Study) exam. Math and science are perceived to be difficult topics and only $3 \%$ of boys and $1 \%$ of girls in grade schools go on to pursue a STEM-related education in college. To make matters worse, there is a shortage of high school students nationwide [5]. Several reports have been issued to draw attention to this crisis. The Business-Higher Education Forum [6] declared that competence in mathematics and science are essential to all individuals. Realizing the seriousness of the crisis, NSF created a new program [7] to promote a strong partnership of stakeholders (college faculty and school teachers) and subject areas. A recent report [8] by President Bush's Science Advisor introduced Computational Science as one of the most important disciplines of the 21st Century. It further stated that progress in Computational Science is seen as a way to ensure America's Competitiveness in a new world of increasing global competition.

\section{CMST Pedagogy: Secondary Schools}

The CMST Institute promotes a strong partnership of higher education and school districts as well as of subject areas (math, science, and technology). While colleges demand better students from school districts (SD), school districts demand better teachers. Their success is interdependent. The partnership of subject areas comes from their interconnectedness as intended by nature. Through computation, one can see the interplay of math, science, and technology to run controlled simulations and scientific inquiries. 
At secondary school level, students cannot be expected to construct mathematical and computer models to run scientific simulations, unless there are tools to make transparent the underlying mathematics, programming, and the detailed scientific content of the experiment. Latest technologies have brought powerful tools to the aid of researchers and educators. It is now possible, indeed, to construct simulations without usual tedious task of programming (FORTRAN, $\mathrm{C}++$, or JAVA) and advanced mathematics. We have used tools such as Interactive Physics [9], AgentSheets [10, Stella 11], Geometer's SketchPad [12, Excel, Project Interactivate (www.shodor.org) and graphing calculator software along with laptops, TI-84 graphing calculators [13] and electronic smartboards [14.

Since 2003, we offered CMST training to more than 265 teachers, with majority being from Rochester City and Brighton Central School Districts. 148 teachers received summer training once (60 hours), 42 teachers twice (108 hours), and 15 teachers three times (156 hours). We also offered, through collaboration with Texas Instruments, TI-certification training (60 hours) to 38 MST teachers. Following the summer workshop, teachers are assigned coaches among college faculty and experienced teachers. They implement CMST-based lessons during the academic year and also participate with their students in the CMST Challenge program. We hold bi-monthly meetings for all faculty, teachers and coaches. CMST Teachers receive laptops, graphing calculators, viewscreens and share electronic smartboards and LCD projectors. Testimonies from teachers show that electronic smart-boards are very effective, as are LCD projectors. According to teacher testimonies, while it usually takes 6 months for a student to come to a blackboard for an in-class demonstration, it only takes 6 hours with the smart board.

Although we rely on teacher and faculty training to impact classroom learning, we reach out directly to middle and high school students as well. In 2005, we reached more than 347 students through Interactive Physics Week and the Challenge Competition. A ceremony was held to display project posters and demonstrations. Outside evaluators judged the projects and selected projects were presented and displayed during the 2005 summer institute. These projects set good examples for CMST integration into classroom teaching as well as how modeling can be applied to solution of real world problems. Evidence thus far has shown that students even at middle school can indeed learn modeling tools and use them to further their knowledge of science and appreciation of math.

Our project evaluators have found a correlation between the number of CMST Teachers in a school and the improvements in student achievement. At the same time, there seems to be a strong correlation between the amount of teacher training and student achievement. As part of institutionalizing our project activities, these trainings are now formalized as credit-bearing college courses and offered outside the summer institute. The CMST training has also been integrated into the professional development days in school districts. Hundreds of CMST-based lesson plans posted on project web site [15] are enhancing our outreach efforts, as they enable CMST teachers to demonstrate to others the effectiveness of the new pedagogy. Instructors from our suburban partner [16] helped us train our 
urban school [17] teachers. Integration of CMST approach and tools has been promoted within the context of NSF-supported Connected Math [18] and Core Plus 19 curricula.

Student achievement improved considerably at Rochester City School District (RCSD) since the beginning of our project in 2003. The district average passing rate reached $90 \%$ in Math-A Regents exam, a 39-point jump from June 2003. Similarly, the district passing rate in state 8 th grade math exam improved by 8 percentage points, from $11 \%$ (2003) to $19 \%$ (2004). In 2005, the district maintained the gains made since 2003 .

Findings from RCSD show a consistent multi-year trend, including: a) students receiving instruction from multiple CMST teachers outperformed students receiving instruction from only one CMST teacher, b) data suggest a correlation between the number of CMST teachers in a given school and the performance of participating students, c) teachers indicate with greater frequency that student performance is improving throughout the school year in their classrooms, d) student performance in technology classrooms exceeded performance in science and math, which probably indicates that students in technology classes have higher access and exposure to CMST tools than others in theoretical math and science classes, e) students taught by beginner-level teachers in 2004 did better than those in 2003, which supports other data that the quality of summer institute got better as years passed as a result of several factors including faculty experience as well as inclusion of peer-teaching, f) academic performance of students participated in the Challenge activity exceeded those who did not, g) attendance of students increased with exposure to CMST pedagogy, and h) dropout rates were lower for students exposed to CMST pedagogy.

Technology access is not a problem at Brighton, contrary to RCSD. A stark contrast between these two districts is that the number of courses and the curriculum seem to be fixed at BCSD while there are many variations and courses within RCSD schools. A similarity between BCSD and RCSD is that Brighton technology treatment classrooms had the highest acceptable grade rate, followed by science and math. This again points out the fact that treatment is maximized in classrooms with adequate technology infrastructure. Another similarity is that although the acceptable grades $(\mathrm{A} / \mathrm{B} / \mathrm{C})$ rate among the suburban-based staff far exceeded that for the urban staff, the trend of the more comprehensively trained teachers from the cohort having more successful students continued. The achievement by students in the Challenge Program in BCSD also exceeded other peer groups within the same school. Three Brighton students [20] in the 2005 Challenge program wrote the following in their report:

Our motivation to prove Kepler's laws has historical significance. As 9th graders, we have not taken any physics course and we are not fully knowledgeable about laws of universe that govern planetary motion. That is not different from the situation of Kepler; as no one quite knew how gravitational forces worked until Newton came. Kepler had access to data compiled by Tycho Brahe and he looked for patterns. We had access to CMST tools and experienced teachers and we looked for miracles! We learned how to transfer visuals images from Interactive Physics 
into Geometer's Sketchpad, which was a tough endeavor all throughout. We also understood better, through Excel, the physical laws and the computational steps involved in Interactive Physics simulations. While we did not make a discovery in physics, we certainly discovered that physics is not a threatening or boring subject after all. The foreboding nature of complicated physics was abolished as we worked on this project and now we look forward to taking AP physics classes offered in our school.

\section{CMST Education: Workforce Preparation}

SUNY Brockport launched the first Computational Science (CPS) undergraduate degree program in the USA in 1998. The department has developed BS, MS, and combined BS/MS degrees in this area, the curricula of which integrate math, computer science, and application sciences. The department has also played an active role in the establishment of other similar programs in the United States and elsewhere. The CPS department has generated workers with practical knowledge and problem solving skills in 3 technical fields (math, science, and technology) to raise quality, adaptability, and versatility of our regional and national workforce. Recruiting and sustaining a sizable student body in a multidisciplinary STEM program is a tough challenge. Thus far, however, the department graduated more than 35 students with both BS and MS degrees; all gainfully employed.

The CPS program is built on seven (7) student learning outcomes, including computational tools, high performance computing, applied and computational math, simulation and modeling, visualization, application sciences, and technical communication [21-31]. It seeks high parameter students who are interested in modeling, programming, and applied mathematical skills in industrial, governmental, and academic settings. Through the minor, the department also seeks students who are interested in learning these skills but not necessarily making them the major focus of their careers. Through general education courses the department seeks to educate the more general college population about the applications and relevance of computational modeling. Through the CMST Institute the department seeks to teach high school and middle school teachers the use of computational modeling software in the classroom, in order to help bring up a more science- and math-literate population.

Preparing a student to credibly learn 3 subject areas (mathematics, computing, and sciences) in 4 years has been a tough challenge. Advising a student body with a broad education base is a challenge for faculty members. The department has gone through 3 major revisions to balance its diversified course work. Even though there is no accreditation in this new field, the department sought peer review from local, regional, and national communities via presentations in conferences and articles in journals [21-31]. Within just 7 years, the department developed and taught 27 new courses, including Introduction to Computational Science, Computational Science Tools I-II, Internet and Technology Ethics, Forensic Computing, History of Science and Technol- 
ogy, High Performance Computing, Simulation and Modeling, Computational Mathematics, Embedded Computing, Computational Chemistry, Computational Physics, Computational Finance, Scientific Visualization, Computational Fluid Dynamics, Computational Biology, Computational Methods for Teachers I-II-III, Advanced Software Tools, Computational Methods in the Physical Sciences, Deterministic and Dynamical Systems, Supercomputing Applications, and Society, Technology, and Science.

Recognizing the difficulties student might face in a multidisciplinary program, the department sought to offer scholarships and internships for students, which created a pipeline of high quality students with internship experiences, employment opportunities, and doctoral assistantships in places such as Harvard, Carnegie-Mellon, Lockheed Martin, Ford, Renselear Polytechnique Institute, George Mason, Sandia National Labs, Eastman Kodak, to name a few. Department faculty members have been very active in recruitment, both domestically and internationally. They developed brochures, posters, and other promotional materials using personal time and took a program from 3 undergraduate students in its first semester to a steady enrollment of 50 undergraduate and graduate students over several years.

As described earlier, the department formed a multi-disciplinary (CMST) institute in 2002, with members from eight departments and two school districts. The institute sponsored funds and team work, and provided a platform for close collaboration between departments and between the college faculty and school teachers. CMST faculty developed several in-service courses for teachers and teacher candidates. These include four natural science courses, two liberal studies courses, and three General Education courses (Internet Ethics, Forensic Computing, and History of Science and Technology). Courses such as Computational Chemistry and Computational Biology (Bioinformatics) are now being taught by their respective departments.

Besides 27 new courses in the department, CPS faculty also taught 15 courses outside the department, particularly in math, computer science, education, and liberal studies programs. The department has continuously and consistently strived to serve the entire college community, and beyond, through curriculum development in which computational modeling is used as a vehicle for understanding. Institute activities led to modifications in more than 20 existing courses in the college, including Forensic Computing, History of Science and Technology, College Geometry, College Algebra, Pre-calculus, Calculus I-II-III, Business Calculus, Finite Math, Math for Elementary Teaching I-II, History of Math, College Physics I-II, Field Methods in Earth Sciences, and Anatomy and Physiology.

Through the grants and equipment donations, the CPS department provided access to supercomputers, high-performance servers, laptops, LCD projectors, graphing calculators, and electronic smart boards for more than 15 faculty members in support of their professional development, scholarly activities, bestpractices, and teaching methodologies. The multidisciplinary aspect of the computational science program attracted large scale funding from the government agencies. The CPS faculty brought the largest single grant (\$3.8 million) in the 
history of our college. Although the CPS department is rather small (3 faculty members), it has provided sponsored funding for more than 12 faculty members in math, computer science, physics, chemistry, earth sciences, biology, and education departments.

CMST, or briefly computational science, has gone through several stages of development as witnessed from the history of our program at Brockport. Leading the nation in CMST education, Brockport program was first to introduce computational science as a discipline of its own, raising it from a mere overlap of mathematics, computer science, and sciences as depicted in [25]. Availability of high performance computer power and wide use of computational techniques in many fields in later stages led to creation of subfields within the computational science community such as computational physics, finance, and others. Today, as witnessed from our own experience, computational science has become a core for many new scientific fields; a role similar to the one played by mathematics. From a new pedagogy to teach math and science to tools for industrial design and to a methodology to perform scientific research, computational science has proven to be a high-return investment area for academia, industry, and public education.

\section{Conclusion}

CMST education is an innovative approach to prepare new generations for the challenges of the information age. The amount of new knowledge is doubling every year and it is a challenge to manage exabytes of digital information created every year. Today's jobs require multiple skills and multiple domains of knowledge. Professionals no longer are specialized in one domain, but in multiple domains. How do we filter this tremendous amount of information and present it in a hierarchical way? The growth of Google (a search engine) is a good indication that filtering and presentation of volumes of data to those who need it is very important. How do we educate new generations?

Technology has changed the way we learn and teach. Campuses nowadays discuss about 'active learning' and seek ways to deliver more content with less cost. We need to better prepare students with general mathematical and computational skills as well as disciplinary knowledge. We need to constantly assess whether we are preparing tomorrow's workforce and leaders. College faculty needs to constantly renew itself in the sea of information. The best way to deal with this is to have a mechanism that will deal with newly created multi-faceted knowledge in a collaborative way. In our CMST experience, we have seen concrete results, ranging from faculty/student quality and quantity in STEM to teacher/student quality in public schools. However, we also recognize a major difficulty to be the lack of necessary human capacity on a single campus. Courses that integrate CMST tools into application fields (science, engineering, business, and humanities) need to be fully developed. Development of student learning outcomes and well-designed assessment strategies, a well-defined curriculum, and a collection of tools and application courses is essential to successfully implement 
a CMST program. Computational science programs need to engage more disciplinary faculty in their campuses or collaborate with each other via distance learning and other digital repositories to enrich resources offered locally.

\section{References}

1. Bureau of Labor Statistics, 2001, http://www.bls.gov/emp/home.htm

2. Courtesy The American Institute of Physics, http://www.aip.org

3. National Science Board, Science and Engineering Indicators, National 1996 Report

4. National Science Foundation, http://www.nsf.gov/statistics

5. New York Times, Feb 5 (2005)

6. Responding to the Crisis in Mathematics \& Science Education, The BusinessHigher Education Forum, http://www.bhef.com

7. NSF Math and Science Partnership Program, http://www.ehr.nsf.gov/msp

8. PITAC Report, Computational Science: Ensuring America's Competitiveness, http://www.nitrd.gov/pitac.

9. Interactive PHysics Website, http://www.interactivephysics.com

10. AgentSheets Website, http://www.agentsheets.com

11. Stella Website, http://www.iseesystems.com

12. Geometer's Sketchpad Website, http://www.keypress.com/sketchpad

13. Texas Instruments Website, http://www.ti.com

14. Blue Ribbon Learning Sites on the Web, http://www.kn.sbc.com/wired/bluewebn

15. CMST Website, http://www.brockport.edu/cmst

16. Brighton School District, http://www.bcsd.org

17. Rochester City School District, http://www.rcsdk12.org

18. NSF-supported Connected Math Project, http://www.math.msu.edu/cmp

19. NSF-supported Core Plus Project, http://www.wmich.edu/cpmp

20. S. Kashyap, J.P. Yaşar, R. Ravago, http://www.brockport.edu/cmst

21. O. Yaşar, J. Maliekal, L. J. Little, D. Jones, Computational Technology Approach to Math and Science Education, IEEE CiSE (to appear)

22. H. Dag, G. Soykan, S. Piskin, and O. Yaşar, CSE Education at Istanbul Technical University. IEEE Comp. in Sci. \& Eng (2005), Vol. 7 (1), 72-77

23. O. Yaşar, CMST Pedagogical Approach to Math and Science Education. LNCS, Vol. 3045 (2004), 807-816

24. H. Dag, G. Soykan, S. Piskin, O. Yaşar, CSE Education, LNCS, Vol. 3045 (2004), 795-806

25. O. Yaşar and R. Landau, Elements of CSE Education. SIAM Review (2003), Vol. $45(4), 787-805$

26. O. Yaşar and R. Landau, Elements of Computational Science Education. Proceedings of SIAM CSE Conference, Feb 2003, San Diego, CA.

27. O. Yaşar, The Bachelor of Science Degree in Computational Science at SUNY Brockport. Proceedings of SIAM CSE Conference. Feb 2003, San Diego, CA.

28. L. Little, The Computational Science Major at SUNY Brockport. FGCS (2003), Vol. 19 (8), 1285-1292

29. O. Yaşar, Computational Science Education: Standards, Learning Outcomes and Assessment. LNCS, Vol. 2073 (2001), 1159-1169

30. O. Yaşar, K. Rajasethupathy, R. Tuzun, A. McCoy, and J. Harkin, A New Perspective on Computational Science Education. IEEE CiSE (2000), Vol. 5 (2), 74-79

31. O. Yaşar, Computational Science Program at SUNY Brockport. Proceedings of the First SIAM CSE Conference, September 21-24 (2000), Wash, D.C., http:// www.siam.org/meetings/cse00 